\title{
Evaporation from a small water reservoir: Direct measurements and estimates
}

\author{
J. Tanny ${ }^{a, *}$, S. Cohen a , S. Assouline ${ }^{a}$, F. Lange ${ }^{a}$, A. Grava ${ }^{a}$, D. Berger $^{\text {b }}$, \\ B. Teltch ${ }^{b}$, M.B. Parlange ${ }^{c}$
}

a Institute of Soil, Water and Environmental Sciences, Agricultural Research Organization, Volcani Center, P.O. Box 6, Bet Dagan 50250, Israel

b Mekorot - The National Water Company, P.O. Box 610, Nazareth Illit 17105, Israel

' School of Architecture, Civil and Environmental Engineering, Ecole Polytechnique Fédérale de Lausanne (EPFL), ENAC/ISTE, Lausanne, Switzerland

Received 30 April 2007; received in revised form 4 November 2007; accepted 8 December 2007

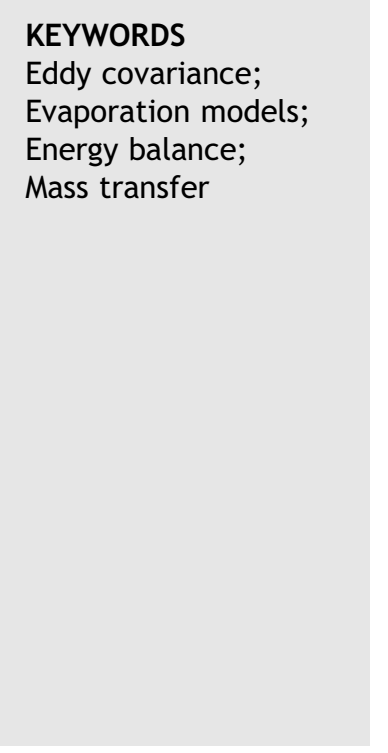

\begin{abstract}
Summary Knowing the rate of evaporation from surface water resources such as channels and reservoirs is essential for precise management of the water balance. However, evaporation is difficult to measure experimentally over water surfaces and several techniques and models have been suggested and used in the past for its determination. In this research, evaporation from a small water reservoir in northern Israel was measured and estimated using several experimental techniques and models during the rainless summer. Evaporation was measured with an eddy covariance (EC) system consisting of a threedimensional sonic anemometer and a Krypton hygrometer. Measurements of net radiation, air temperature and humidity, and water temperature enabled estimation of other energy balance components. Several models and energy balance closure were evaluated. In addition, evaporation from a class-A pan was measured at the site. EC evaporation measurements for 21 days averaged $5.48 \mathrm{~mm}^{-1}{ }^{-1}$. Best model predictions were obtained with two combined flux-gradient and energy balance models (Penman-Monteith-Unsworth and Penman-Brutsaert), which with the water heat flux term, gave similar daily average evaporation rates, that were up to $3 \%$ smaller than the corresponding EC values. The ratio between daily pan and EC evaporation varied from 0.96 to 1.94. The bulk mass transfer coefficient was estimated using a model based on measurements of water surface temperature, evaporation rate and absolute humidity at 0.9 and $2.9 \mathrm{~m}$ above the water surface, and using two theoretical approaches. The bulk transfer coefficient
\end{abstract}

\footnotetext{
* Corresponding author. Tel.: +972 3 9683410; fax: +972 39604017.

E-mail address: tanai@volcani.agri.gov.il (J. Tanny).
} 
was found to be strongly dependent on wind speed. For wind speeds below $5 \mathrm{~m} \mathrm{~s}^{-1}$ the estimated coefficient for unstable conditions was much larger than the one predicted for neutral conditions.

(c) 2007 Elsevier B.V. All rights reserved.

\section{Introduction}

One of the major problems in the management of surface water resources, such as water reservoirs or channels, is the estimation of all water budget components. Such knowledge is necessary for regulating water supply in response to demand, for identification and estimation of possible percolation through the reservoir or channel floor and for chemical analysis of reservoir water. In water reservoirs, for example, it may be relatively easy to measure inflow, outflow and precipitation. However, to identify whether percolation through the reservoir floor takes place, water balance closure is necessary which requires an accurate estimate of the evaporation losses. Therefore, evaporation from water bodies has been the topic of many studies throughout the years (see Lenters et al., 2005, and references therein).

A common and relatively simple approach for estimating evaporation is the measurement of standard meteorological parameters (net radiation, air temperature and humidity and wind speed) and the use of Penman (Penman, 1948) or Priestley-Taylor (Priestley and Taylor, 1972) equations (Brutsaert, 1982). The Penman equation or its PenmanBrutsaert variation (Brutsaert, 1982, p. 218; Katul and Parlange, 1992) is an analytical solution of the combined heat and mass transfer and energy balance equations for a wet surface. Penman derived constants for water bodies based on research in lakes. However, to solve this equation, information is needed not only on the external meteorological conditions but also on the heat storage within the water body, which requires temperature profile measurements within the water (Stanhill, 1994). If the air has been in contact with the water surface for a very long fetch, equilibrium evaporation may be assumed where the air is saturated with water vapor (Brutsaert, 2005). The Priestley-Taylor equation utilizes equilibrium evaporation as the basis for an empirical relationship describing evaporation from a wet surface under minimal advection. For this case the Penman equation is simplified and only the radiative term is preserved and multiplied by an empirically determined constant. There are many other equations used to estimate evaporation. Warnaka and Pochop (1988) analyzed six different evaporation equations and Winter et al. (1995) evaluated 11 equations for estimating evaporation from a small lake in the north central Unites States. The latter study showed that three equations, i.e., modified DeBruin-Keijman, Priestley-Taylor and modified Penman, resulted in monthly evaporation values that agreed most closely with energy budget values.

Evaporation can be measured directly with the eddy covariance (EC) technique, where fluctuations of vertical velocity and vapor density are measured at high frequency. If applied under certain limitations, this technique is typically considered today as the most reliable and accurate for evaporation estimation (Itier and Brunet, 1996). In
Israel, EC was used to measure evaporation from Lake Kinneret (Assouline and Mahrer, 1993; Assouline, 1993) with a measuring station situated about $200 \mathrm{~m}$ offshore, east of the western coast of the lake. EC has been used for evaporation measurements from other lakes and reservoirs (Sene et al., 1991; Stannard and Rosenberry, 1991; Allen and Tasumi, 2005). EC can also measure the sensible heat flux, a major component of the energy balance, and thus can give insight into the dynamics of the Bowen ratio (i.e. the ratio of sensible to latent heat flux), which is widely used in evaporation estimates.

Although some work has been published on evaporation from lakes and large water reservoirs, it appears that evaporation from small reservoirs has not been measured with EC techniques before and that current estimation techniques may not provide detail of the same order of magnitude as that of current monitoring of inflow and outflow rates of small reservoirs. Thus, the major goal of the present research was to determine evaporation from such a reservoir and to compare several determination approaches: the direct eddy covariance measurement technique, standard class-A pan measurements and evaporation models based on flux-gradient, energy balance, and mass transfer approaches.

\section{Theoretical considerations}

\section{Evaporation models}

Several models were employed to estimate evaporation and compare with the direct measurements of the EC system. One type of model tested is based on a combination of the energy balance principle and the flux-gradient approach. Models of this type can be represented by (Brutsaert, 1982, p. 216 and Monteith and Unsworth, 1990, p. 185):

$\lambda E=\frac{\Delta}{\Delta+\gamma^{*}}(R n-G)+\frac{\gamma^{*}}{\Delta+\gamma^{*}} E_{A}$

where $\lambda E\left(\mathrm{~W} \mathrm{~m}^{-2}\right)$ is the latent heat flux, $\Delta\left(\mathrm{Pa} \mathrm{K}^{-1}\right)$ is the rate of increase of saturation pressure with temperature, $R n\left(\mathrm{~W} \mathrm{~m}^{-2}\right)$ is net radiation, $G\left(\mathrm{~W} \mathrm{~m}^{-2}\right)$ is the sum of ground $\left(G_{B}\right)$ and water $\left(G_{S}\right)$ heat fluxes, $\gamma^{*}=0.93 \gamma$ (Monteith and Unsworth, 1990, p. 183), where $\gamma$ is the psychrometric constant, and $E_{A}$ is an atmosphere drying function which represents the capacity of the atmosphere to transport water vapor (Brutsaert, 2005, p. 126).

The first model of this type is the Penman model for a wet surface (Monteith and Unsworth, 1990, p. 185) hereafter referred to as PMU, in which:

$E_{A}=\frac{\rho c_{p}}{r_{\mathrm{a}} \gamma^{*}}\left[e_{\mathrm{s}}(T)-e\right]$

where $\rho\left(\mathrm{kg} \mathrm{m}^{-3}\right)$ is air density, $c_{p}\left(\mathrm{~J} \mathrm{~kg}^{-1} \mathrm{~K}^{-1}\right)$ is air specific heat, $T(\mathrm{~K})$ is the air temperature and $e(\mathrm{~Pa})$ is vapor pressure with subscript $s$ indicating saturation. The aerodynamic 
resistance $r_{\mathrm{a}}\left(\mathrm{s} \mathrm{m}^{-1}\right)$ is given by (Brutsaert, 1982, Eq. (10.19)):

$r_{\mathrm{a}}=\frac{\ln \left(z_{m} / z_{0 m}\right) \ln \left(z_{v} / z_{0 v}\right)}{k^{2} \bar{u}}$

where $z_{m}(m)$ and $z_{v}(m)$ are respectively, the heights of wind speed and vapor density measurements, $\bar{u}\left(\mathrm{~m} \mathrm{~s}^{-1}\right)$ is mean horizontal wind speed and the momentum roughness length is $z_{0 m}=u_{*}^{2} /(81 \mathrm{~g})(\mathrm{m}) \quad($ Charnock, 1955, 1958 as quoted by Brutsaert, 1982, Eq. (5.8)) where $u_{*}\left(\mathrm{~m} \mathrm{~s}^{-1}\right)$ is the friction velocity. $k=0.41$ is the von-Kármán's constant and $g=9.8 \mathrm{~m} \mathrm{~s}^{-2}$ is the gravitational acceleration. The scalar roughness length for the rough water surface under study was chosen as that of a bluff-rough surface, so $z_{0 v}=$ $7.4 z_{0 m} \exp \left[-2.25\left(z_{0 m} u_{*} / v\right)^{1 / 4}\right]$ (Brutsaert, 1982, Eq. (5.28) and p. 124), where $v\left(\mathrm{~m}^{2} \mathrm{~s}^{-1}\right)$ is air kinematic viscosity. Using measured standard meteorological data along with three components of turbulent wind speed (used for the estimation of the friction velocity $u_{*}$, see Section "Data processing') the latent heat flux can be estimated.

The second model is the Penman-Brutsaert model (Brutsaert, 1982, p. 218; Katul and Parlange, 1992), hereafter referred to as $\mathrm{PB}$, in which

$E_{A}=f(u)\left[e_{\mathrm{s}}(T)-e\right]$

where $f(u)$ is a wind function which includes corrections due to atmospheric non-neutral stability. Following Katul and Parlange (1992; Eqs. (2)-(11)) an iterative procedure can be employed to calculate the latent heat flux. In this method, there is no need to know the friction velocity in advance and thus it can be utilized on the basis of standard meteorological measurements only. Nevertheless, the friction velocities measured in the present study and the expression given by Charnock $(1955,1958)$ were used to provide a first guess for the momentum roughness length which then was incorporated in the iterative procedure of this model. The expression for the scalar roughness length, $z_{O v}$, was similar to the one used in the PMU model above.

The third and fourth models of this type have the same structure as Eq. (2.4), however, to avoid the iterative solution, two different empirical simplified expressions for $f(u)$ were applied (Brutsaert, 2005, p. 127). The first, proposed by Penman (1948) for open water (hereafter referred to as P) is $f(u)=0.26\left(1+0.54 u_{2}\right)$ and the second, proposed by Doorenbos and Pruitt (1975) for a wet crop surface (hereafter referred to as PDP is $f(u)=0.26\left(1+0.86 u_{2}\right)$, where $u_{2}$ is the wind speed measured at $2 \mathrm{~m}$ height. In these expressions the constants require that $E_{A}$ in (2.4) is in $\mathrm{mm} \mathrm{day}^{-1}$ and the vapor pressure in millibar. In applying these expressions, wind speed measured at $2.4 \mathrm{~m}$ was corrected to $2 \mathrm{~m}$ assuming a logarithmic wind profile.

A simple variation of Eq. (2.1) has been proposed by Priestley and Taylor (1972) who suggested that evaporation into air moving over an extensive area of uniform wetness exceeds the equilibrium value of $\lambda E_{\text {eq }}=\left(\Delta /\left(\Delta+\gamma^{*}\right)\right)\left(R_{n}-G\right)$ by a factor of 1.26 (Brutsaert, 2005, p. 129). The Priestley-Taylor model is hereafter referred to as PT.

Another type of model tested in this research, based on the mass transfer approach, assumes that water vapor flux takes place across a vapor pressure gradient in the boundary layer adjacent to the water surface. Assuming that mass transfer is a linear function of wind speed, latent heat flux, $\lambda E\left(\mathrm{~W} \mathrm{~m}^{-2}\right)$ is then calculated as (Brutsaert, 1982, p. 217):

$\lambda E=\left(a+b \bar{u}_{1}\right)\left(e_{\mathrm{s}}-e_{2}\right)$

where $\bar{u}_{1}\left(\mathrm{~m} \mathrm{~s}^{-1}\right)$ is mean horizontal wind speed, $e(\mathrm{~Pa})$ is the air vapor pressure and the linear wind function with parameters $a\left(\mathrm{~m} \mathrm{~s}^{-1}\right)$ and $b$ (dimensionless) computes boundary layer transfer coefficients. The subscripts 1 , s and 2 represent the height of wind speed measurement, the water surface and height of vapor pressure measurement, respectively. Eq. (2.5) allows for evaporation when wind speed is zero, which, as shown in our results below, is a distinct advantage.

Mass transport is also described by a single dimensionless bulk transfer coefficient Ce (Brutsaert, 2005, p. 119), i.e.:

$E=\operatorname{Ce} \rho \bar{u}_{1}\left(\bar{q}_{\mathrm{s}}-\bar{q}_{2}\right)=\operatorname{Ce} \bar{u}_{1}\left(\bar{\chi}_{\mathrm{s}}-\bar{\chi}_{2}\right)$

where $E\left(\mathrm{~kg} \mathrm{~m}^{-2} \mathrm{~s}^{-1}\right)$ is the evaporation rate, $q\left(g_{w} g_{a}^{-1}\right)$ is the specific humidity and $\chi\left(g_{w} \mathrm{~m}^{-3}\right)$ is absolute humidity. Strictly speaking, if $\mathrm{Ce}$ is a constant, this formulation does not allow for evaporation when wind speed is zero, in contrast with Eq. (2.5). If one adopts Eq. (2.6) Ce can be estimated empirically by determining the slope of a regression line of measured values of $E /\left(\bar{\chi}_{s}-\bar{\chi}_{2}\right)$ on wind speed $\bar{u}_{1}$, while forcing that regression line through the origin.

The empirical approach described by Eq. (2.5), which allows for evaporation at zero wind speed, can lead to

$E=\rho\left(\alpha+\beta \bar{u}_{1}\right)\left(\bar{q}_{\mathrm{s}}-\bar{q}_{2}\right)=\left(\alpha+\beta \bar{u}_{1}\right)\left(\bar{\chi}_{\mathrm{s}}-\bar{\chi}_{2}\right)$

where the linear wind function with parameters $\alpha\left(\mathrm{m} \mathrm{s}^{-1}\right)$ and $\beta$ (dimensionless) computes the appropriate transfer coefficients. Ce derived by comparing Eq. (2.6) with (2.7), is then:

$\mathrm{Ce}=\alpha / \bar{u}_{1}+\beta$.

A general theoretical expression for $\mathrm{Ce}$ under nonneutral atmospheric conditions takes into account stability correction functions. The stability of the surface layer is characterized by the Monin-Obukhov stability parameter:

$\zeta=\frac{z-d}{L}$

where $\mathbf{z}$ is the height above the surface, $d$ is zero-plane displacement (for the water surface this can be taken as zero) and $L$ is the Monin-Obukhov length scale, defined as (Brutsaert, 1982, p. 65):

$L=\frac{-u_{*}^{3} \rho}{k g\left[\left(\frac{H}{T c_{p}}\right)+0.61 E\right]}$

where in this expression $H\left(\mathrm{~W} \mathrm{~m}^{-2}\right)$ is the sensible heat flux. In this analysis, $H$ and $E$ are taken from the eddy covariance measurements described below.

The bulk transfer coefficient under non-neutral conditions can be estimated theoretically as (Brutsaert, 1982, p. 122):

$\mathrm{Ce}=k C d^{0.5}\left[\ln \left(\frac{z}{z_{0 v}}\right)-\Psi_{\mathrm{sv}}\left(\frac{z}{L}\right)\right]^{-1}$

where the roughness length $\mathrm{z}_{0 v}$ is similar to that used in Eq. (2.3). Here, the drag coefficient is defined as (Brutsaert, 1982, Eq. (4.115)): 
$\mathrm{Cd}=\frac{u_{*}^{2}}{\bar{u}_{1}}$

where $\bar{u}_{1}$ is horizontal mean wind speed. The profile function $\psi_{\mathrm{sv}}$ is given by (Brutsaert, 1982, Eq. (4.46)):

$\Psi_{\mathrm{sv}}(\zeta)=2 \ln \left[\frac{\left(1+x^{2}\right)}{\left(1+x_{0 v}^{2}\right)}\right]$

where $x=(1-\beta \zeta)^{1 / 4}, x_{0 v}=\left(1-\beta \zeta_{0 v}\right)^{1 / 4}, \zeta_{0 v}=\left(z_{0 v} / L\right)$, and for unstable conditions $(\zeta<0), \beta=16$ (Brutsaert, 1982, $\mathrm{p}$. 68).

Under neutral conditions $(\zeta=0)$, it can be shown that the general expression in Eq. (2.11) is reduced to (Brutsaert, 2005, p. 120):

$$
\mathrm{Ce}=\frac{k^{2}}{\ln \left(\frac{z_{2}}{z_{0 \mathrm{v}}}\right) \ln \left(\frac{z_{1}}{z_{0 m}}\right)}
$$

where $z_{0 m}$ is similar to that defined in Eq. (2.3).

Using Eqs. (2.14) and (2.11) we can calculate a theoretical Ce under neutral and unstable conditions, respectively. On the other hand, when evaporation, air humidity, and wind speed data are available, plotting $\frac{E}{\overline{\gamma_{s}}-\overline{\gamma_{2}}}$ against wind speed and determining the slope and intercept of the linear regression gives empirical estimates for $\alpha$ and $\beta$ and Ce can be presented as a function of wind speed using Eq. (2.8).

\section{Energy balance}

The energy balance of a water body with inlet and outlet channels can be expressed as

$R n-G_{\mathrm{S}}-G_{\mathrm{B}}+\frac{\rho_{\mathrm{w}} V}{A} C_{p \mathrm{w}}\left(T_{w \mathrm{i}}-T_{\text {wo }}\right)=\lambda E+H$

where $G_{\mathrm{S}}\left(\mathrm{W} \mathrm{m}^{-2}\right)$ is water heat flux (hereafter denoted as WHF), $G_{B}\left(W^{-2}\right)$ is the heat flux to the reservoir bottom, (we define $\left.G=G_{\mathrm{S}}+G_{\mathrm{B}}\right)$, $\rho_{\mathrm{W}}\left(\mathrm{kg} \mathrm{m}^{-3}\right)$ is water density, $V$ $\left(\mathrm{m}^{3} \mathrm{~s}^{-1}\right)$ is water volume flow rate, $A\left(\mathrm{~m}^{2}\right)$ is surface area, $c_{p \mathrm{w}}\left(\mathrm{J} \mathrm{kg}^{-1} \mathrm{~K}^{-1}\right)$ is water specific heat, $T_{\mathrm{w}}(\mathrm{K})$ is water temperature and $\lambda\left(\mathrm{kJ} \mathrm{kg}^{-1}\right)$ is the latent heat of vaporization. Indexes $\mathrm{i}$ and $\mathrm{o}$ designate inlet and outlet water flow, respectively.

\section{Site description and methods}

The research was carried out at the Eshkol reservoir (BetNetofa valley in northern Israel, $32^{\circ} 46^{\prime} \mathrm{N}$; 35 $5^{\circ} 15^{\prime} \mathrm{E}, 145$ m.a.s.l), a part of the National Water Carrier system operated by Mekorot, the Israel National Water Company. This is a settling reservoir which receives water intermittently, by gravity flow in an open channel, from another upstream reservoir of the same system, the Tsalmon reservoir. Eshkol is a square reservoir with a $600 \mathrm{~m}$ side and $3.5 \mathrm{~m}$ depth. Water flows out of this reservoir into a larger adjacent operational reservoir at the same site. Being a settling reservoir, it is kept at an almost constant water level. Most measurements were conducted during 21 days in 2005 on days of year (DOY) 209-215 (July 28 to August 3), 245-253 (September 2-10) and 256-260 (September 13-17). Wind speed measurements with the three-dimensional sonic anemometer (see details below) were also conducted in 2005 during an additional 28 days, on days of year 216-229 (August 4-
17), 233-244 (August 21 to September 1) and 254-255 (September 11 and 12 ), i.e. during a total of 49 days.

The measurements were conducted at the reservoir center on a permanent $2.2 \times 2.2 \mathrm{~m}$ square platform mounted on four vertical steel beams $0.75 \mathrm{~m}$ above the mean water level. The platform location at the reservoir center allowed a minimum fetch of $300 \mathrm{~m}$ in all wind directions. The eddy covariance $(E C)$ system consisted of a three-dimensional sonic anemometer (model 81000, R.M. Young, USA) and a krypton hygrometer (model KH20, Campbell Sci., Logan, UT, USA). Sensor height was $2.4 \mathrm{~m}$ above the water surface level, within the equilibrium surface layer. Using data collected in the present measurements it was shown that under typical boundary layer properties the farthest edge of the $90 \%$ source area was about $170 \mathrm{~m}$ away from the EC sensors (Schmid, 1997) and the thickness of the equilibrium boundary layer was approximately $5 \mathrm{~m}$ above the water surface level (Munro and Oke, 1975; Rao, 1975). Thus, there is no doubt that the EC sensors captured evaporation from a large part of the water body under study and not from external sources. To minimize wind distortion effects, eddy covariance sensors were deployed on an arm, extending about $2.5 \mathrm{~m}$ away from the platform structure towards the north-west, the direction of the prevailing wind. Sensors were operated at a $10 \mathrm{~Hz}$ sampling rate and averages and covariances were calculated every $15 \mathrm{~min}$. Eddy covariance raw data were corrected using the procedures suggested by Horst (2003) and Tanner and Greene (1989). Sonic temperature sampled by the sonic anemometer was converted to temperature (using the measured air humidity) and used for sensible heat flux measurements. For part of the measurement period (DOY 209-215), a one-dimensional sonic anemometer (model CA27, Campbell Sci., USA) was also deployed and covariances were calculated simultaneously using the data of the two anemometers (one-dimensional and three-dimensional). The two measurements were in good agreement. The three-dimensional sonic anemometer was also used to collect high frequency wind data for analysis of the turbulent characteristics of the wind. Full data were recorded at a rate of $10 \mathrm{~Hz}$ during the first $4 \mathrm{~min}$ of each hour.

Additional measurements were carried out to study the energy balance of the reservoir. Net radiation was measured with a net radiometer $(Q * 7.1$, REBS, USA) installed $1 \mathrm{~m}$ above the water surface, mounted on an arm extending about $2 \mathrm{~m}$ away from the platform. Dry and wet bulb air temperatures were measured by two aspirated psychrometers shielded from direct solar radiation and positioned 0.9 and $2.9 \mathrm{~m}$ above the water surface.

Water temperatures were measured near the platform with insulated T-type thermocouples attached to a steel cable at 7 depths within the reservoir at $0.5 \mathrm{~m}$ intervals. Water temperature measurements were carried out during 14 days (DOY 245-253 and DOY 256-260). Water temperatures within the reservoir were also measured by a mobile temperature profiler (STD, Applied Microsystems, Canada) at nine different locations (sub-regions) over the reservoir area: three profiles were measured at the southern region (SW, SC and SE, representing inlet temperature), three profiles at the central region (CW, CC and CE) and three profiles at the northern region of the reservoir (NW, NC and NE, representing outlet water temperature) where $\mathrm{S}, \mathrm{W}, \mathrm{N}$ and $\mathrm{E}$ 
represent the common compass directions and $\mathrm{C}$ represents central region. Each profile consisted of 5-10 data points, measured during a period of about $5 \mathrm{~min}$. Five sets of nine profiles each were recorded from a boat on days of year: 158 (June 7), 219 (August 7), 244 (September 1) and 257 ( 2 sets, September 14). Each set of 9 profiles took about $60 \mathrm{~min}$, including the time taken for the boat to move from point to point. Water temperatures were also measured at the inlet and outlet water streams, but due to technical problems none of these measurements were good during the period that the EC system was operational. All sensors (except for the EC and mobile profiler) were sampled at a rate of $0.2 \mathrm{~Hz}$ and $15 \mathrm{~min}$. averages were recorded.

Data collection other than for the profiler was with Campbell Sci. (Logan UT) systems. On the central platform a CR23X data logger monitored the EC system components at $10 \mathrm{~Hz}$, and a CR21X data logger, AM32 multiplexer and SM192 storage module monitored all other sensors at $0.2 \mathrm{~Hz}$. These were powered by two $62 \mathrm{AH}$ car batteries charged by solar panels. The CR23X was fitted with a cellular phone link for remote monitoring and hourly data retrieval during daylight.

A standard class-A pan was installed at the center of the eastern bank of the reservoir, $2 \mathrm{~m}$ above water level. Wind at the site was mostly westerly $(88 \%$ of the time the wind azimuth was between $180^{\circ}$ and $360^{\circ}$ ), so air flowing above the pan was predominantly from the reservoir. Pan measurements were carried out during a relatively long time period in summer 2005, but they overlapped with valid EC data only during 7 days of the year (DOY 247-250 and 256-258).

\section{Data processing}

The logarithmic wind profile in a neutral atmosphere is given by:

$u(z)=\frac{u_{*}}{k} \ln \left(\frac{z-d}{z_{0 m}}\right)$,

from which the friction velocity can be extracted:

$\frac{u_{*}}{k}=u(z) / \ln \left(\frac{z-d}{z_{0 m}}\right)$.

Appropriate values for $d$ and $z_{O m}$ were used, based on the surface characteristics. For water surfaces it is common to use $d=0$ because if the water surface at dead calm is taken as the reference, then wave crests caused by wind are offset by the troughs in between; i.e. the average height of the surface is unchanged. The roughness length used here was

$\mathrm{z}_{0 m}=u_{*}^{2} /(b g)$

as suggested by Charnock (1955) and quoted by Brutsaert (1982, p. 117 , Eq. $(5.8)$ ) where $u_{*}$ in this expression is the friction velocity estimated from the measurements of the three-dimensional sonic anemometer (Eq. (4.5)). The constant $b=81$ (Charnock, 1958) and the gravitational acceleration is $g=9.8 \mathrm{~m} \mathrm{~s}^{-2}$.

The instantaneous velocity vector $(U, V, W)$ can be decomposed into mean and turbulent components in the $x, y$ and $z$ directions (where $x$ and $y$ are horizontal coordinates and $z$ is the vertical coordinate):
$U=U_{\mathrm{m}}+u^{\prime}$

$V=V_{\mathrm{m}}+v^{\prime}$

$W=W_{\mathrm{m}}+W^{\prime}$

where $U_{\mathrm{m}}, V_{\mathrm{m}}$ and $W_{\mathrm{m}}$ are the mean velocities and $u^{\prime}, v^{\prime}$ and $W^{\prime}$ are their turbulent counterparts.

Horizontal friction velocity is calculated directly from measured wind speed components (measured at $10 \mathrm{~Hz}$ ) as

$u_{*}=\left(\left\langle u^{\prime} w^{\prime}\right\rangle^{2}+\left\langle v^{\prime} w^{\prime}\right\rangle^{2}\right)^{1 / 4}$.

The instantaneous horizontal velocity component is defined as

$U_{\mathrm{h}}=\sqrt{\left(U^{2}+V^{2}\right)}$

and the mean horizontal velocity is

$U_{\mathrm{hm}}=\left\langle\sqrt{U^{2}+V^{2}}\right\rangle$,

where the symbol $\langle R\rangle$ represents a time average of any variable $R$. Horizontal r.m.s. velocity, $U_{\mathrm{h}}^{\text {r.m.s. }}$ is defined as the standard deviation of $U_{\mathrm{h}}$ and the normalized r.m.s. velocity or turbulence intensity is defined as

$I=U_{\mathrm{h}}^{\text {r.m.s. }} / U_{\mathrm{hm}}$.

In general, turbulence intensity is a quantity that characterizes the intensity of gusts in the airflow.

Turbulence has a wide range of length (time) scales. It is commonly accepted that fluctuation energy is produced at the large eddies (with low wave numbers and frequencies). The vortex stretching mechanism then generates smaller and smaller eddies and energy flows down the spectrum to the high wave number (and frequency) region. Thus, spectral analysis is a widely used tool in the study of turbulent flows.

Energy spectra of the three wind velocity components (see Stull, 1988 for details) were calculated from detrended records of the 4-min $10 \mathrm{~Hz}$ data by applying the MATLAB's FFT (fast Fourier transform) algorithm. Each 4-min period was subdivided into 10 consecutive sections, each with 240 data points. A spectrum was calculated for each section and the 10 resulting values were averaged. The spectrum of each velocity component was calculated separately and their sum, the spectrum of the total energy, also known as the three-dimensional spectrum (Tennekes and Lumely, 1972), was determined.

\section{Results}

\section{Turbulence characteristics of the boundary layer above the water surface}

Friction velocity $\left(\boldsymbol{u}_{*}\right)$ calculated from measured wind components by Eq. (4.5) is compared in Fig. 1 with that calculated for the logarithmic wind profile model (Eq. (4.2)). The roughness length in the logarithmic model was estimated with Eq. (4.3). Linear regression of the 1176 data points yielded the relation:

$u_{* \text { meas }}=0.84 u_{* \text { mod }}+0.059 \quad\left(R^{2}=0.7\right)$

Thus, reasonable agreement was obtained between measured and predicted data, which suggests that a logarithmic wind profile is common above the water surface. The addi- 


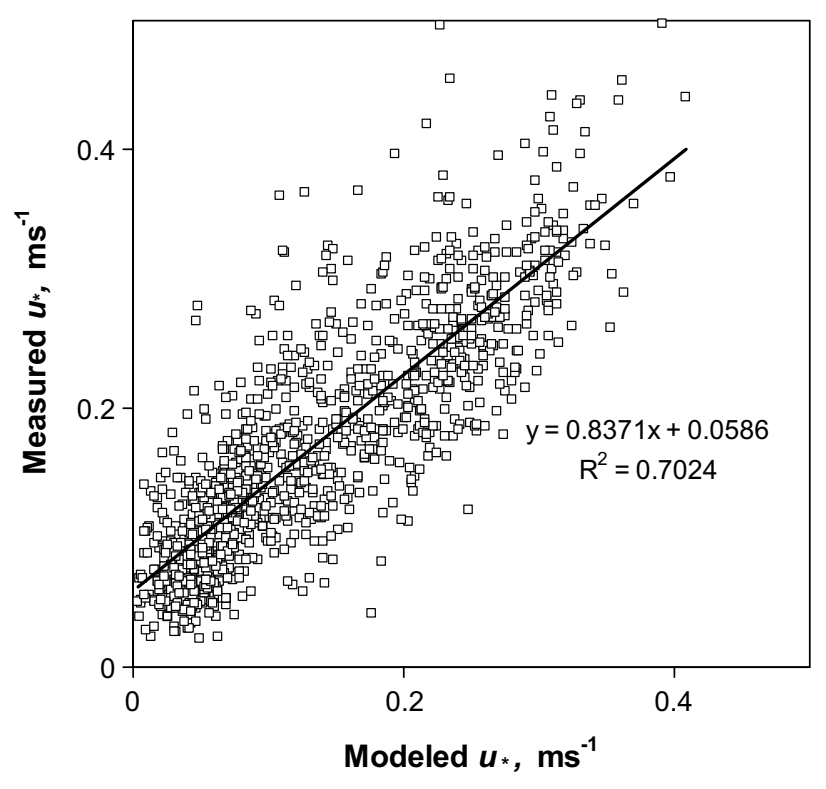

Figure 1 Friction velocity calculated directly from the measurements (Eq. (4.5)) plotted against that predicted by the logarithmic wind profile model (Eq. (4.2)). The solid line is the least square regression line, where $y=0.84 x+0.06\left(R^{2}=\right.$ $0.7,1176$ data points).

tion of a stability correction function to the logarithmic wind profile did not improve the agreement between measured and predicted friction velocity.

Normalized r.m.s velocity or turbulence intensity (Eq. (4.8)) of the horizontal wind speed averaged $0.19 \pm 0.006$ during the 49 days of wind speed measurement (a total of 1176 values, each for a 4-min time period), where \pm indicates the $95 \%$ confidence interval. Turbulence intensity was larger than 0.5 in only 25 out of the 1176 data points, with a maximum value of 1.52 . According to Willis and Deardorf (1976), Taylor's hypothesis of 'frozen' turbulence is valid when turbulence intensity is less than 0.5 . Under this condition, the turbulent eddies evolve on a time scale much larger than the time it takes the eddy to be advected past the sensors (Stull, 1988). The present results therefore suggest that Taylor's hypothesis is satisfied in the boundary layer above the water surface.

Normalized power spectra of the air velocity above the water show the strength of the fluctuations (energy) as a function of frequency. In other words, they show at which frequencies fluctuations are strong and at which frequencies they are weak. Results show that low frequencies were the most energetic and the magnitude of the energy increased with mean air speed, as expected. Slopes of regression fits to the spectra for a logarithmic relationship were calculated for different days and hours of the day and all were found to be close to $-5 / 3(-1.67)$, the value corresponding to the inertial sub-range in steady state turbulent boundary layers (Stull, 1988).

\section{Flux measurements}

During several days latent heat flux was measured simultaneously by the EC system with both one-dimensional and three-dimensional sonic anemometers and a mutual Krypton hygrometer. Good agreement was observed between the two sets of raw data, and for the 7 day period (DOY 209215) the least squares linear relationship between the two gave a slope of 0.91 and $R^{2}$ of 0.9 . We also used the least normal squares (LNS) method to estimate the slope of the relation between the two datasets. This method (Hirsch and Gilory, 1984) is useful when comparing two measurements that are expected to be equally valid since it minimizes squared errors normal to the best fit line (i.e. minimizes both squared errors) in comparison to the ordinary least squares (OLS) technique which minimizes the squares only in the vertical ( $Y$-axis) direction. The slope obtained using the LNS method was 0.89 , almost the same as that obtained with the OLS technique. All other results in this paper were based on EC measurements with the three-dimensional sonic anemometer.

Fig. 2 presents diurnal curves of net radiation and latent and sensible heat flux for two days, DOY 209 and 210 (July 28 and 29, 2005). Positive latent heat flux (i.e. evaporation) was observed during both the days and nights. Night time evaporation apparently dissipated heat stored in the water during the day. The time lag of several hours between the peaks of net radiation and evaporation is also evidence for energy storage in or heat flux into the water. Evaporation and sensible heat flux, which represent consumed energy, are less than the net radiation, so additional energy sinks are needed to close the energy balance. For example, during the 21-day period of measurements average 15-min value of $L E+H$ is $162.6 \mathrm{~W} \mathrm{~m}^{-2}$ whereas average $R n$ is 191.8 $\mathrm{W} \mathrm{m}^{-2}$. These observations indicate that water heat flux plays a significant role in this system, as discussed below.

Daily evaporation determined from the 15-min interval EC results is presented in Fig. 3 in units of $\mathrm{mm} \mathrm{day}^{-1}$ for the 21 days of measurement (DOY 209-215, 245-253 and 256-260). Average daily evaporation over this period was $5.48 \pm 1.1 \mathrm{~mm} \mathrm{day}^{-1}( \pm 1 \mathrm{SD})$. The relatively uniform daily evaporation reflects the nearly constant meteorological conditions prevailing in the site during the summer months of July, August and September.

Pan evaporation data measured during the 7 days when EC data were also available gave an average daily evaporation rate of $9.63 \pm 1.5 \mathrm{~mm} \mathrm{day}^{-1}( \pm 1 \mathrm{SD})$, which is $65 \%$ higher

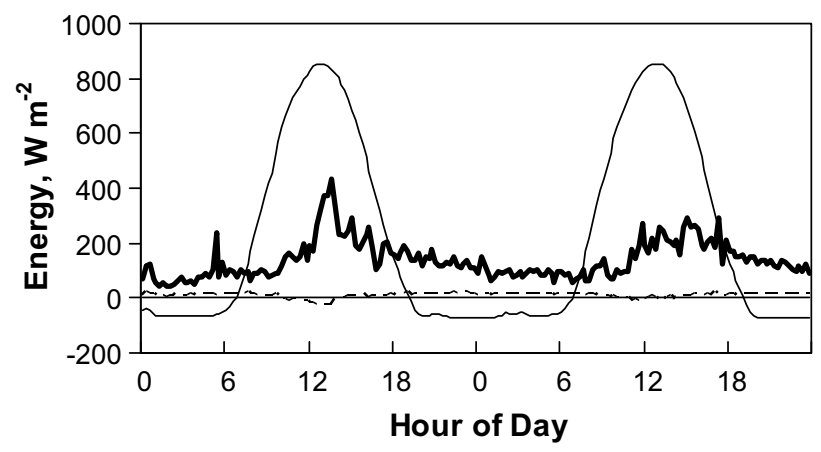

Figure 2 Diurnal curves of net radiation (light solid line), latent heat flux (heavy solid line) and sensible heat flux (dashed line), during July 28 and 29. 


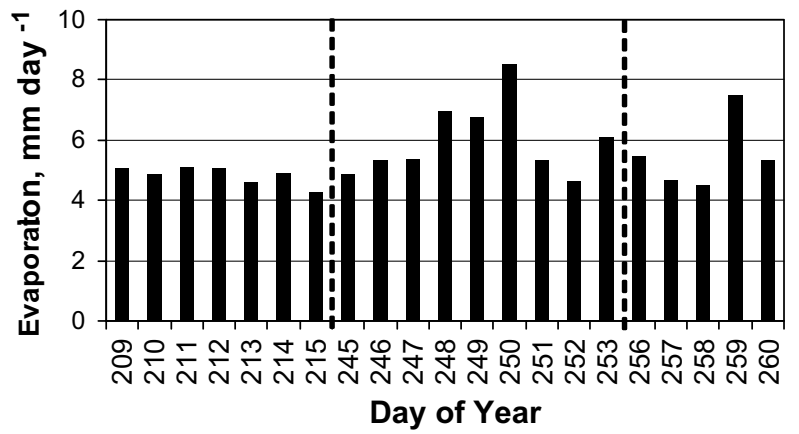

Figure 3 Daily evaporation measured by the eddy covariance technique during the 21 days of measurement from July 28 (DOY 209) to September 17 (DOY 260). Vertical dashed lines indicate time gaps.

than the corresponding average daily EC value, $5.83 \pm 1.27 \mathrm{~mm} \mathrm{day}^{-1}$. On six of the seven days pan evaporation was higher than EC by at least $50 \%$ and the ratio of daily pan to EC evaporation varied from 0.96 to 1.94 , indicating that pan evaporation usually exceeded evaporation from the reservoir.

\section{Water temperature}

Temperatures of inlet and outlet water flows were measured during several days in the fall after the EC measurements stopped. These measurements indicated a general trend of cooling of the water as it traverses from the inlet region (south) to the outlet region (north) of the reservoir, i.e., in Eq. (2.15), $T_{w i}$ is higher than $T_{\text {we }}$. The vertical profiles of water temperature measured by the mobile profiler at 9 cells over the reservoir were averaged over the reservoir depth, resulting in a single mean value for each of the 9 cells (see Section "Site description and methods"). The water temperature difference between the south and north parts of the reservoir was calculated separately for the western, central and eastern thirds of the reservoir. For example, for the western third the temperature difference between south and north, $T_{\mathrm{sw}}-T_{\mathrm{nw}}$, was calculated as the difference between the corresponding southern and northern cells. The average of the three temperature differences between south and north was also calculated. Results of the four temperature difference values for the five sets of measurements are shown in Fig. 4. The results show two cases where the temperature increased (August 7 and September 1) and three sets where it decreased during water flow from the south to the north sides of the reservoir. These data, then, do not allow simple generalizations on the dynamics of water temperature during its flow and the associated energy storage in the reservoir.

\section{Energy balance closure}

Evaluation of energy balance closure in the reservoir system required estimating all energy balance components in Eq. (2.15). Net radiation $(R n)$ and latent $(L E)$ and sensible $(H)$ heat flux terms are presented in Section "Flux measurements" above. Spatial temperature variations showed that streamwise temperature gradients were sometimes positive

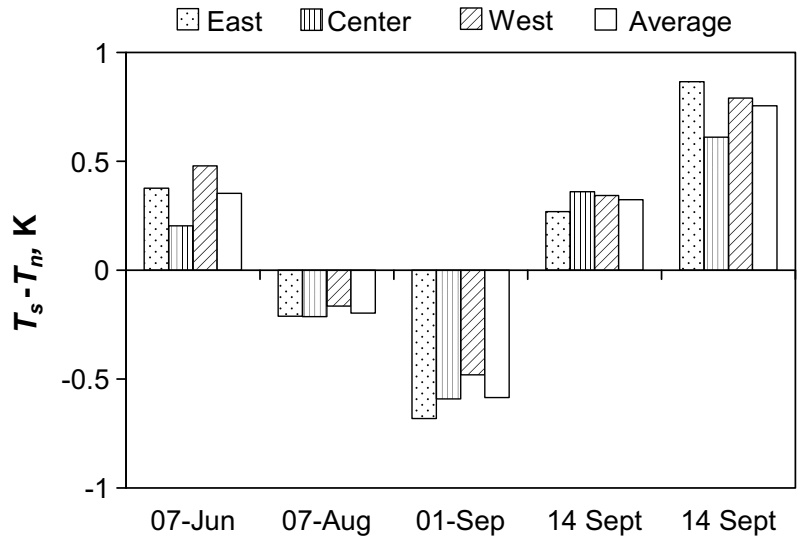

(1)

(2)

Figure 4 Temperature differences between the southern (inlet) and northern (outlet) sides of the reservoir. Bar patterns represent different thirds of the reservoir, and blank bars represent the average. Each data set (cluster of four bars) was calculated based on profiles measured at 9 cells. Hours of data collection: June 7 - 13:00; August 7 - 09:00; September 1 09:00; September 14(1) - 08:30; September 14(2) - 12:00.

and sometimes negative (see Section "Water temperature'"). Thus, energy entering or leaving the reservoir, expressed by the last term on the left-hand side of Eq. (2.15), was assumed to cancel out when integrated over several days. The water heat flux (WHF) term $G_{S}$ was estimated using continuous records of water temperatures at 7 depths near the platform, available for 14 days. Recalling that water depth was constant in the reservoir, $G_{S}$ was estimated by calculating the time variation of energy content in a unit area of the water volume. Vertical temperature profiles suggested that the temperature gradient near the reservoir floor is relatively small $\left(<0.6^{\circ} \mathrm{C} \mathrm{m}^{-1}\right)$ and so heat exchange between the water body and the floor $\left(G_{\mathrm{B}}\right)$ was also neglected. Thus, the energy balance, Eq. (2.15) is reduced to:

$R n-G_{\mathrm{S}}=L E+H$

where in Eq. (5.2) the left-hand side is available energy and the right-hand side is consumed energy.

Analysis of the daily WHF $\left(G_{S}\right)$ term determined from the temperature profiles suggested days with either positive or negative extremes of the WHF term. We take this as an indication that the energy balance requires analysis over a period longer than one day. These extreme values of WHF may result from intermittent flow of water through the reservoir due to temporal changes in water demand, from random errors in temperature measurement or from turbulence in the water body.

The energy balance closure expressed by Eq. (5.2) is shown in Fig. 5. Energy dissipated by evaporation and convection $(L E+H)$ is presented against the available energy $\left(R n-G_{\mathrm{S}}\right)$. A unit slope and zero intercept would represent perfect closure of the energy balance.

The solid straight line has slope and intercept of 0.36 and $3.7 \mathrm{~mm}$, respectively, which indicate significant departure from a closed energy balance. Several daily points significantly deviate from the 1:1 line and four such data points 


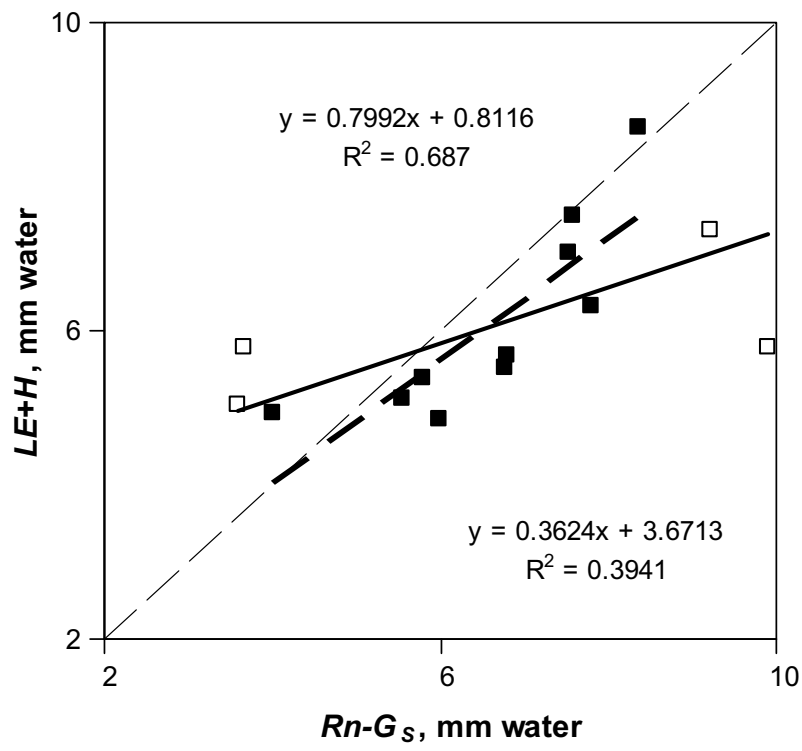

Figure 5 Dissipated versus available energy. The light dashed line has a 1:1 slope. The solid line was fitted to all data points using the least squares technique with the equation $y=0.36 x+3.67, R^{2}=0.39$. The heavy dashed line was fitted to the full square data points only with the equation $y=0.8 x+0.8, R^{2}=0.69$. The empty squares represent days with significant deviation from the 1:1 line.

are marked by empty squares. These four points correspond to days where extreme WHF values were recorded. Least squares analysis of the other data points (full squares) resulted in the heavy dashed line with slope and intercept of 0.8 and $0.8 \mathrm{~mm}$, respectively. This slope is in reasonable agreement with slopes obtained for a large variety of inland flux measurements (Wilson et al., 2002). Thus, closure of the energy balance on a daily basis is significantly improved by removing these four data points.

Integrating the 14 days of measurement gave total $R n-$ $G_{S}$ of $92.5 \mathrm{~mm}, L E+H$ of $84.9 \mathrm{~mm}$, and $G_{S}=-1.44 \mathrm{~mm}$.
Thus, for a time period of 14 days the water heat flux is small and the difference between available and dissipated energy is only $9 \%$ of $L E+H$, which represents reasonable closure of the energy balance. The latter supports the validity of the EC measured sensible and latent heat fluxes in this study.

\section{Evaporation models}

\section{Penman type combination equations}

Several models have been tested in this study (Section "Evaporation models"). The five models: Penman-Monteith-Unsworth (PMU), Penman-Brutsaert (PB), models with empirical expressions for $E_{\mathrm{A}}$ ( $\mathrm{P}$ and $\mathrm{PDP}$ ) and Priestley-Taylor (PT), are based on the energy balance of the water body. These five models were calculated three times: (i) assuming zero water heat flux $\left(G_{S}\right)$ for the whole 21-day period (ii) assuming zero water heat flux $\left(G_{\mathrm{S}}\right)$ for the 14-day period, where $G_{\mathrm{S}}$ was measured and (iii) using $G_{\mathrm{S}}$ (calculated using the time variation of water temperature profiles) for the 14-day period (starting on DOY 245). For each of the five models, average daily evaporation was calculated in $\mathrm{mm}$ day $^{-1}$ over the relevant period (either 21 or 14 days).

To test the performance of each model the Nash-Sutcliffe efficiency coefficient (Nash and Sutcliffe, 1970) was also calculated and is shown in parentheses in each italicised values of Table 1 . This coefficient, $C$, is calculated as

$$
C=1-\frac{\sum_{n}\left(\mathrm{EC}_{n}-\mathrm{MOD}_{n}\right)^{2}}{\sum_{n}\left(\mathrm{EC}_{n}-\overline{\mathrm{EC}_{n}}\right)^{2}}
$$

Here EC and MOD indicate measured and modeled daily values $\left(\mathrm{mm}\right.$ day $\left.^{-1}\right)$, subscript $n$ indicates daily value and over bar indicates an average over the measurement period (either 14 or 21 days). Nash-Sutcliffe efficiency can range from $-\infty$ to 1 . An efficiency coefficient of $1(C=1)$ corresponds to a perfect match of modeled to measured data. A coefficient of $0(C=0)$ indicates that the model predictions are as accurate as the mean of the observed data, whereas a coefficient less than zero $(-\infty<C<0)$ occurs when the observed mean is a better predictor than the mod-

Table 1 Average daily evaporation $\left(\mathrm{mm} \mathrm{day}^{-1}\right) \pm 1$ SD as measured by the eddy covariance (EC) technique and as predicted by five models: Penman-Monteith-Unsworth (PMU), Penman-Brutsaert (PB), Priestley-Taylor (PT), Penman (P) and PenmanDoorenbos-Pruitt (PDP)

\begin{tabular}{llll}
\hline Approach & $\begin{array}{l}\text { Assuming zero WHF, } \\
\text { 21 day average }( \pm \text { SD })\end{array}$ & $\begin{array}{l}\text { Assuming zero WHF, } \\
14 \text { day average }( \pm \text { SD })\end{array}$ & $\begin{array}{l}\text { Using measured WHF, } \\
14 \text { day average }( \pm \text { SD })\end{array}$ \\
\hline Actually measured $(\mathrm{EC})\left(\mathrm{mm} \mathrm{day}^{-1}\right)$ & $5.48 \pm 1.10$ & $5.81 \pm 1.2$ & $5.81 \pm 1.2$ \\
PMU Model $\left(\mathrm{mm} \mathrm{day}^{-1}\right)$ & $6.32 \pm 0.53$ & $6.13 \pm 0.36$ & $5.83 \pm 2.16$ \\
PB Model $\left(\mathrm{mm} \mathrm{day}^{-1}\right)$ & $6.19 \pm 0.51$ & $6.01 \pm 0.35$ & $5.65 \pm 2.16$ \\
PT Model $\left(\mathrm{mm} \mathrm{day}^{-1}\right)$ & $6.84 \pm 0.70$ & $6.50 \pm 0.34$ & $6.12 \pm 2.63$ \\
P Model $\left(\mathrm{mm} \mathrm{day}^{-1}\right)$ & $7.29 \pm 0.51$ & $7.22 \pm 0.47$ & $6.89 \pm 2.19$ \\
PDP Model $\left(\mathrm{mm} \mathrm{day}^{-1}\right)$ & $8.05 \pm 0.59$ & $8.06 \pm 0.59$ & $7.72 \pm 2.26$ \\
Ratio: PMU/EC & $1.15(-0.70)$ & $1.06(0.20)$ & $1.00(-1.20)$ \\
Ratio: PB/EC & $1.13(-0.52)$ & $1.04(0.24)$ & $0.97(-1.23)$ \\
Ratio: PT/EC & $1.25(-2.22)$ & $1.12(-0.26)$ & $1.05(-2.60)$ \\
Ratio: P/EC & $1.33(-2.66)$ & $1.24(-1.08)$ & $1.19(-2.00)$ \\
Ratio: PDP/EC & $1.47(-5.41)$ & $1.39(-3.27)$ & $1.33(-3.89)$
\end{tabular}

The last five rows (italicised) indicate the ratios between the daily average measured evaporation (by the EC) and the respective models. The numbers in parentheses which are italicised indicate the Nash-Sutcliffe efficiency coefficient, $C$, for each model. 
el. Essentially, the closer $C$ is to 1 , the more accurate the model is.

Results are summarized in Table 1. The first row (denoted by EC) is the average daily evaporation measured by EC. The next five rows give the average daily evaporation rates predicted by the models. The last five rows (italicised) are the ratios of the predicted values to the measurements. The $( \pm)$ indicates one standard deviation of the average. The Nash-Sutcliffe efficiency of each model is given in parentheses in the italicised values of Table 1.

Table 1 shows that inclusion of the WHF has two effects: (i) on average, it improves the agreement between measured and predicted values as seen by the fact that the ratios (italicised) in the 3rd column are closer to unity than those in the 2 nd column for the same 14 day period. (ii) It increases the variability of the daily data as seen by the higher standard deviation in the 3rd column, as compared to the 1 st and 2 nd columns. This is presumably due to the influence of extreme WHF on certain days. The latter is supported by the $C$ values (in parentheses) which become worse (i.e. smaller than 1) when WHF is included in the 14-day set.

The Nash-Sutcliffe coefficient $C$ indicates how well the models "follow" the variations in the measured values on a daily basis, and thus the effect of extreme daily values of WHF is to reduce (and deteriorate) $C$ values. For the cases where WHF is ignored the daily analysis performs better (as indicated in the energy balance analysis in Section "Energy balance closure") and therefore $C$ is closer to unity as shown in the 2 nd column of Table 1.

Table 1 shows that the Penman-Monteith-Unsworth (PMU) and the Penman-Brutsaert (PB) models gave average daily evaporation (over 14 days) closest to the average measured value. Thus, it appears that these two models are the most reliable under the conditions of the present study. The next best model is Priestley-Taylor (PT) followed by the Penman (P) and Penman-Doorenbos-Pruitt (PDP) models.

\section{Mass transfer models}

Analysis of the 2016 data points obtained during 21 days of measurement showed that $98 \%$ of the time conditions in the surface layer were unstable, i.e. $\zeta<0$. Therefore analysis was done for unstable atmospheric conditions only. Table 2 presents the regression results for the mass transfer model parameters (from Eqs. (2.6) and (2.8)) and Fig. 6 presents a comparison with theoretical estimations.

A least squares comparison of Ce calculated by the wind function of Eq. (2.8) and that calculated theoretically by Eq. (2.11) under unstable conditions resulted in a slope of 0.74 $\left(R^{2}=0.67\right)$ for the $0-0.9 \mathrm{~m}$ data set and a slope of 0.7 $\left(R^{2}=0.69\right)$ for the $0-2.9 \mathrm{~m}$ data, indicating a reasonable correlation between the two approaches. Fig. 6 presents
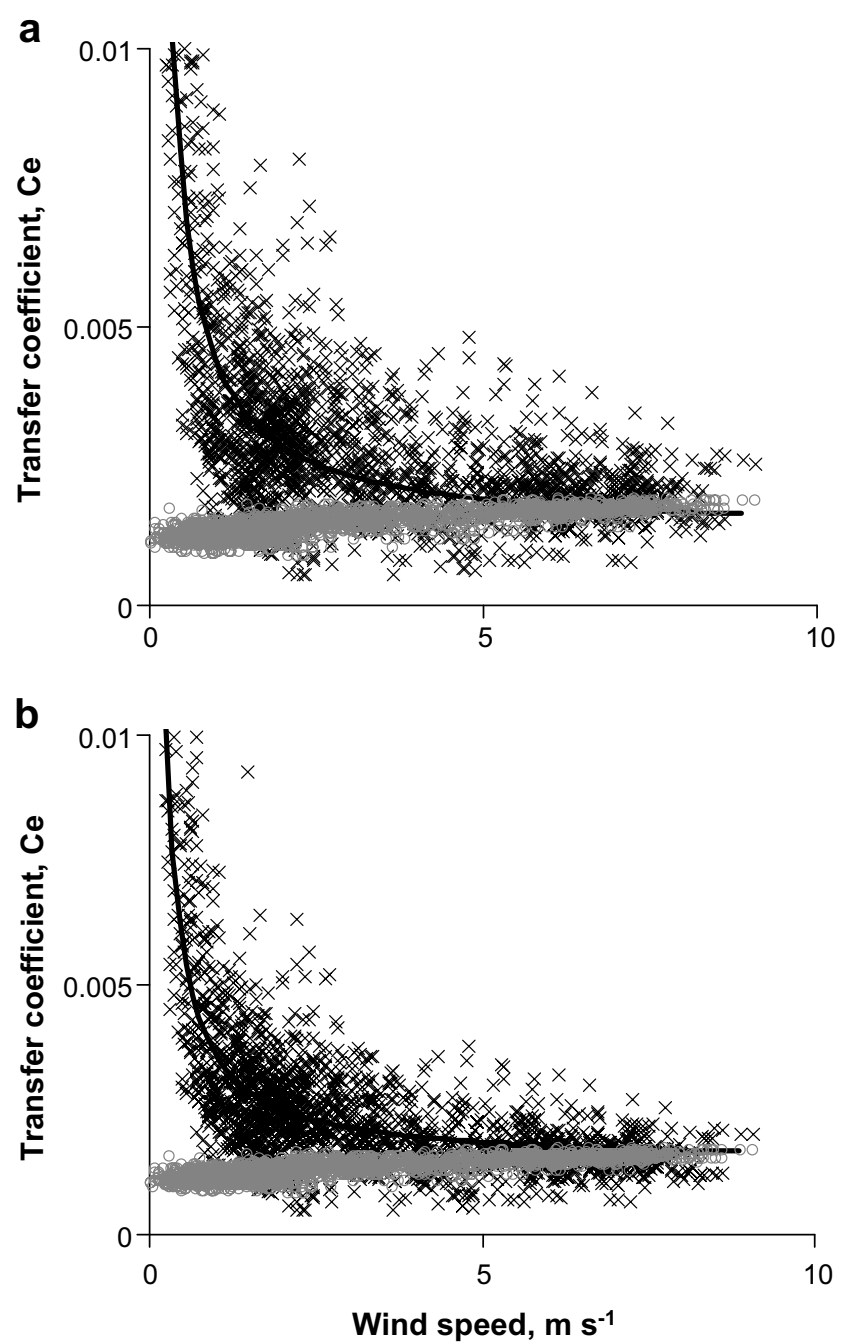

Figure 6 Dimensionless transfer coefficients as a function of wind speed for $0-0.9 \mathrm{~m} \mathrm{(a)}$ and $0-2.9 \mathrm{~m} \mathrm{(b)}$. Theoretical neutral (gray round symbol) and unstable $(\times$ symbol) values were computed from Eqs. (2.14) and (2.11), respectively. The data points are $15 \mathrm{~min}$ averages. The solid line gives the results of the regression analysis described by Eq. (2.8) using the values of $\alpha$ and $\beta$ from Table 2 .

these results as a function of wind speed along with the results obtained using the expression for Ce under neutral conditions (Eq. (2.14)). The results in Fig. 6 show very good agreement between the results of the regression analysis (solid line; Table 2) and theoretical values (Eq. (2.11), $\times$ symbols). Both show essentially the same strong dependence of Ce on wind speed, especially for wind speeds lower than about $5 \mathrm{~m} \mathrm{~s}^{-1}$.

Table 2 Regression results for $\alpha$ and $\beta$ (from regression), and constant Ce (from regression forced through the origin) for unstable atmospheric conditions, as described by Eqs. (2.8) and (2.6), respectively

\begin{tabular}{llllll}
\hline Parameter units $(\mathrm{m})$ & $\alpha\left(\mathrm{m} \mathrm{s}^{-1}\right)$ & $\beta$ (dimensionless) & $R^{2}$ & Constant Ce (dimensionless) & $R^{2}$ \\
\hline $0-0.9$ & $3.100 \times 10^{-3}$ & $1.293 \times 10^{-3}$ & 0.65 & $1.942 \times 10^{-3}$ & 0.41 \\
$0-2.9$ & $2.189 \times 10^{-3}$ & $1.418 \times 10^{-3}$ & 0.64 & $1.877 \times 10^{-3}$ & 0.55 \\
\hline
\end{tabular}

$n=1970$. All $R^{2}$ values are significant at $p<0.001$. 
For wind speeds above $5 \mathrm{~m} \mathrm{~s}^{-1}$ the calculated Ce values at neutral conditions approach the values estimated for an unstable atmosphere. This implies that in the present study relatively high wind speeds tend to be associated with relatively small values of $\zeta$, because under such values of $\zeta$, the general expression for non-neutral Ce (Eq. (2.11)) reduces to the one for neutral conditions (Eq. (2.14)). For example, analysis of the $0-2.90 \mathrm{~m}$ data set (including unstable, neutral and stable conditions) showed that in $44 \%$ of the data points where wind speed was $>5 \mathrm{~m} \mathrm{~s}^{-1}$, conditions were near neutral, i.e., $-0.03<\zeta<0.03$.

\section{Discussion}

Direct measurements of evaporation from a small reservoir were carried out using an eddy covariance system deployed at the center of the reservoir. The system consisted of a three-dimensional sonic anemometer and a krypton hygrometer. Some of the measurements were compared with daily evaporation data measured by a class-A pan on the reservoir's bank. Additional sensors were deployed to measure other components of the energy balance, i.e. sensible heat flux, net radiation and water heat flux and heat gain or loss.

Evaporation measured by the EC technique during a period of 21 days (selected days in July, August and September 2005) averaged $5.48 \pm 1.10 \mathrm{~mm} \mathrm{day}^{-1}( \pm 1 \mathrm{SD})$. Daily pan evaporation, which covered only 7 days, significantly exceeded reservoir evaporation. The reason for this difference is presumably the significantly different thermal condition of the pan water as compared to reservoir water. The pan cannot store energy over this time period while the reservoir has significant energy storage capacity and can gain or lose energy through in and outflow. The pan, which was deployed on a raised platform, may have had enhanced advective heat flux through its sides and bottom. These differences could easily explain the differences in evaporation, but they were beyond the scope of our research.

An average pan coefficient of 0.65 can be deduced from the 7 days where data for both pan and EC were available. This value is similar to the "crop" pan coefficient (e.g. Allen et al., 1998), which expresses the ratio between well watered reference crop evapotranspiration and pan evaporation. Since the ratio between daily evaporation from the reservoir and the pan was highly variable, it appears that the pan was not a reliable predictor under the conditions of this study. However more data is needed to make specific recommendations.

Two terms in the energy balance (Eq. (2.15)) are related to the water temperature. The energy gain or loss due to the change of water temperature between the south region (near the inlet) and north region (near the outlet) was deduced from five sets of measurements of the vertical water temperature profiles at different locations in the reservoir (Fig. 6). This data suggested that water may either cool or warm during its flow from the south to the north, reflecting the unsteady nature of the water flow associated with the intermittent water demand, which significantly affects the dynamics of the relatively small reservoir under study. Analysis of the limited data leads to the assumption that over a long time period this term will cancel out. This was also confirmed by the finding that integrating the 14 days of measurement gave a 9\% difference between available and consumed energy. Consequently, the contribution of this term to the energy balance was neglected in the present analysis.

Another significant term is the water heat flux, $G_{S}$, estimated here from the temporal change of the water temperature in the middle of the reservoir. Closure of the energy balance on a daily basis using this data was poor. However, on a longer term basis the storage was small and the closure was improved; over a period of 14 days consumed energy was only $9 \%$ lower than the available energy. This period (14 days) is equal to the minimum period used by Lenters et al. (2005) in their long term energy balance analysis of evaporation from Sparkling Lake (USA), or by Assouline and Mahrer (1993) in Lake Kinneret (Israel).

Evaporation measured by EC was compared with estimates of a number of models. These were based on either mass transfer or 'combination' flux-gradient and energy balance approaches. For some of the models standard meteorological data such as air temperature and humidity, net radiation, wind speed and water surface temperature are sufficient; other models require data collected by more sophisticated instrumentation like the three-dimensional sonic anemometer necessary for the estimation of friction velocity.

In general, some agreement was found between average values of the direct measurements and the 'combination' models with deviations ranging from $0 \%$ up to $47 \%$ (Table 1). Best performance was obtained from the PMU and PB models in which the wind functions are most elaborated. The PB model also includes stability correction functions and thus is apparently preferable to the other models in which neutral stability is assumed. The rest of the models (PT, $P$ and PDP), which include either a constant wind effect (PT) or empirical constants for the wind function ( $P$ and PDP), deviated more significantly from the direct measurements.

Inclusion of the water heat flux term in the models based on the energy balance principle (i.e., Penman and its variations) always improved the agreement with the direct measurements over a long time period. However, on a daily basis, the Nash-Sutcliffe efficiency coefficient showed that including the water heat flux in the model calculations deteriorated the agreement with measurements as compared to modeling without water heat flux. To illustrate the influence of decreasing the time period we calculated the Nash-Sutcliffe efficiency on a 15-min basis. For the PMU model (as an example) inclusion of WHF changed the efficiency from -5.1 (without storage) to -33 . This shows that as the time step is reduced from a day to $15 \mathrm{~min}$, inclusion of water heat flux has an increasingly detrimental effect on the agreement between model and measurements. This conclusion is also in agreement with analysis of the energy balance closure (Fig. 5), which showed that removing certain days when extreme water heat flux values were measured improved the closure. These analyses support the use of long term measurements for determining evaporation from energy budgets of water bodies.

Assuming a constant bulk transfer coefficient the values obtained here, e.g. $1.88 \times 10^{-3}$ at $2.9 \mathrm{~m}$ height, were some- 
what smaller than those reported by Sene et al. (1991), i.e. $2.3 \times 10^{-3}$ at a measurement height of $4.2 \mathrm{~m}$ and for wind speeds above $3 \mathrm{~m} \mathrm{~s}^{-1}$. Our values agree with those of Ikebuchi et al. (1988), $0.08 \times 10^{-3}$ to $2.1 \times 10^{-3}$ for a measurement height of $6 \mathrm{~m}$.

When bulk transfer coefficients are presented as a function of wind speed, Ce calculated from a theoretical expression for non-neutral conditions showed very good agreement with values determined empirically by linear regression, for wind speeds up to $9 \mathrm{~m} \mathrm{~s}^{-1}$. For wind speeds below $5 \mathrm{~m} \mathrm{~s}^{-1}$, different theoretical values were obtained for neutral and unstable conditions while at higher wind speeds $\left(>5 \mathrm{~m} \mathrm{~s}^{-1}\right)$ results for unstable and neutral conditions were nearly the same. Moreover, theoretical considerations show that under conditions of neutral stability $(\zeta=0)$ the general expression for non-neutral $\mathrm{Ce}$ is reduced to the one for neutral stability. This implies that in the present study, conditions of high wind speed tend to be associated with neutral stability, presumably due to enhancement of turbulent mixing with increasing wind speed.

As discussed by Winter et al. (1995), a disadvantage of models based on the mass transfer approach as compared to the energy balance principle is that in the former, a calibrated mass transfer coefficient must be determined based on direct evaporation measurements whereas in the latter evaporation can be estimated using standard meteorological data.

\section{Conclusions}

Evaporation rates from a small water reservoir were obtained by direct eddy covariance measurement and estimated using several models. The following main conclusions can be drawn from this study:

1. Best agreement between predicted evaporation and direct measurements was obtained using the models with elaborated wind functions (PMU and $\mathrm{PB}$ ) as compared to the models with simplified wind functions ( $P, P D P)$ or a constant wind contribution (PT). Including the water heat flux term improved the agreement between predictions and measurements only for long time periods (14 days). On a daily basis, ignoring this term resulted in better agreement between predictions and measurements.

2. For the small reservoir studied, water heat flux may significantly influence the reservoir energy balance closure on a daily basis, but for longer (e.g. 14-day) time periods the influence is small.

3. The mass transfer coefficient was strongly related to wind speed. Results suggest that at relatively high wind speeds atmospheric conditions in the surface layer tend to approach neutral stability. Thus for wind speeds above $5 \mathrm{~m} \mathrm{~s}^{-1}$, the relatively simple expression for the mass transfer coefficient for neutral conditions can be used with reasonable accuracy.

4. Pan evaporation usually overestimated the reservoir evaporation directly measured by the EC technique.

These results may be useful for the analysis of water balance closure and identification of possible percolation through the reservoir's floor, which is otherwise very difficult to estimate.

\section{Acknowledgements}

The authors thank Shlomo Shoshani and the staff of the Watershed Unit of Mekorot Ltd., for their collaboration. The authors thank an anonymous reviewer whose comments improved the original version of this paper considerably. This research was funded by Mekorot, The Israel National Water Company, under research Contract No. 304-0333-05. This support is gratefully acknowledged.

Contribution of the Institute of Soil, Water and Environmental Sciences, Agricultural Research Organization, No. 605/07.

\section{References}

Allen, R.G., Pereira, L.S., Raes, D., Smith, M., 1998. Crop evapotranspiration - guide for computing crop water requirements, FAO Irrigation and Drainage Paper No. 56, Rome.

Allen, R.G., Tasumi, M., Evaporation from American Falls reservoir in Idaho via a combination of Bowen ratio and eddy covariance. In: Proceedings of the 2005 EWRI Conference, Anchorage, AK, May 15-19, pp. 1-17.

Assouline, S., 1993. Estimation of lake hydrologic budget terms using the simultaneous solution of water, heat and salt balances and a Kalman filtering approach - application to Lake Kinneret. Water Resour. Res. 29, 3041-3048.

Assouline, S., Mahrer, Y., 1993. Evaporation from Lake Kinneret. A. Eddy correlation system measurements and energy balance estimates. Water Resour. Res. 29, 901-910.

Brutsaert, W., 1982. Evaporation into the Atmosphere: Theory, History and Applications. D. Reidel Publishing Co., Dordrecht, Holland, 299pp.

Brutsaert, W., 2005. Hydrology: An Introduction. Cambridge University Press, New York.

Charnock, H., 1955. Wind stress on a water surface. Quart. J. Roy. Meteor. Soc. 81, 639-640.

Charnock, H., 1958. A note on empirical wind-wave formulae. Quart. J. Roy. Meteor. Soc. 84, 443-447.

Doorenbos, J., Pruitt, W.O., 1975. Crop water requirements, FAO Irrigation and Drainage Paper No. 24 FAO Rome, 179pp.

Hirsch, R.M., Gilory, E.J., 1984. Methods of fitting a straight line to data: examples in water resources. Water Resour. Bull., Am. Water Resour. Assoc. 20, 705-711.

Horst, T., 2003. Corrections to sensible and latent heat flux measurements. <http://www.atd.ucar.edu/rtf/facilities/isff/ heat_fluxes.shtml>. NCAR/Atmospheric Technology Division.

Ikebuchi, S., Seki, M., Ohtoh, A., 1988. Evaporation from Lake Biwa. J. Hydrol. 102, 427-449.

Itier, B., Brunet, Y., 1996. Recent developments and present trends in evaporation research: a partial survey. In: Camp, C.R., Sadler, E.J., Yoder, R.E. (Eds.), Evapotranspiration and Irrigation Scheduling, Proceedings of the International Conference. ASAE, Texas, pp. 1-20.

Katul, G.G., Parlange, M.B., 1992. A Penman-Brutsaert model for wet surface evaporation. Water Resour. Res. 28 (1), 121-126.

Lenters, J.D., Kratz, T.K., Bowser, C.J., 2005. Effects of climate variability on lake evaporation: results from a long-term energy budget study of Sparkling Lake, northern Wisconsin (USA). J. Hydrol. 308, 168-195.

Monteith, J.L., Unsworth, M.H., 1990. Principles of Environmental Physics. Arnold, London.

Munro, D.S., Oke, T.R., 1975. Aerodynamic boundary-layer adjustment over a crop in neutral stability. Bound-Lay. Meteorol. 9, 53-61.

Nash, J.E., Sutcliffe, J.V., 1970. River flow forecasting through conceptual models: Part I - A discussion of principles. J. Hydrol. 10, 282-290. 
Penman, H.L., 1948. Natural evaporation from open water, bare soil and grass. Proc. Royal Soc. London A 193, 120-145.

Priestley, C.H.B., Taylor, R.J., 1972. On the assessment of surface heat flux and evaporation using large-scale parameters. Mon. Weather Rev. 100, 81-92.

Rao, K.S., 1975. Effect of thermal stratification on the growth of the internal boundary layer. Bound-Lay. Meteorol. 8, 227-234.

Sene, K.J., Gash, J.H.C., McNeil, D.D., 1991. Evaporation from a tropical lake: comparison of theory with direct measurements. J. Hydrol. 127, 193-217.

Schmid, H.P., 1997. Experimental design for flux measurements: matching scales of observations and fluxes. Agr. Forest Meteorol. $87,179-200$.

Stannard, D.I., Rosenberry, D.O., 1991. A comparison of short-term measurements of lake evaporation using eddy correlation and energy budget methods. J. Hydrol. 122, 15-22.

Stanhill, G., 1994. Changes in the rate of evaporation from the Dead Sea. Int. J. Climatol. 14, 465-471.

Stull, R.B., 1988. An Introduction to Boundary Layer Meteorology. Kluwer, The Netherlands.
Tanner, B.D., Greene, J.P., 1989. Measurement of Sensible Heat and Water Vapor Fluxes using Eddy Correlation Methods. Campbell Scientific Inc., Logan, USA.

Tennekes, H., Lumely, J.L., 1972. A first course in turbulence. MIT Press, USA.

Warnaka, K., Pochop, L., 1988. Analyses of equations for free water evaporation estimates. Water Resour. Res. 24 (7), 979-984.

Willis, G.E., Deardorf, J.W., 1976. On the use of Taylor's translation hypothesis for diffusion in the mixed layer. Quart. J. Royal Soc. A 164, 476-490.

Wilson, K., Goldstein, A., Falge, E., Aubinet, M., Baldocchi, D., Berbigier, P., Bernhofer, C., Ceulemans, R., Dolman, H., Field, C., Grelle, A., Ibrom, A., Law, B.E., Kowalski, A., Meyers, T., Moncrieff, J., Monson, R., Oechel, W., Tenhunen, J., Valentini, R., Verma, S., 2002. Energy balance closure at FLUXNET sites. Agr. Forest Meteorol. 113, 223-243.

Winter, T.C., Rosenberry, D.O., Sturrock, A.M., 1995. Evaluation of 11 equations for determining evaporation for a small lake in the north central United States. Water Resour. Res. 31 (4), 983-993. 